Department of Genetics, Children's

Hospital of Eastern

Ontario, 401 Smyth

Road, Ottawa, Ontario

K1K 1N2, Canada

C M Armour

A G W Hunter

\section{Ottawa Hospital}

Research Institute and

Division of Neurology,

Ottawa Hospital, 501

Smyth Road, Ottawa,

Ontario K1H 8L6,

Canada

D E Bulman

Correspondence to:

Dr Hunter

Revised version received

1 November 1999

Accepted for publication

29 November 1999

\title{
Clinical and radiological assessment of a family with mild brachydactyly type A1: the usefulness of metacarpophalangeal profiles
}

\author{
C M Armour, D E Bulman, A G W Hunter
}

\section{Abstract}

The brachydactylies are a group of conditions in which various subtypes have been defined based upon the specific pattern of digital bones involved. Type A1 brachydactyly is principally characterised by maximal involvement of the middle phalanges. We report an extended family with a mild brachydactyly A1 which was, except for some short stature, not associated with any of the additional clinical findings reported in several published families. While all the hand bones tended to be small, the principal features of the

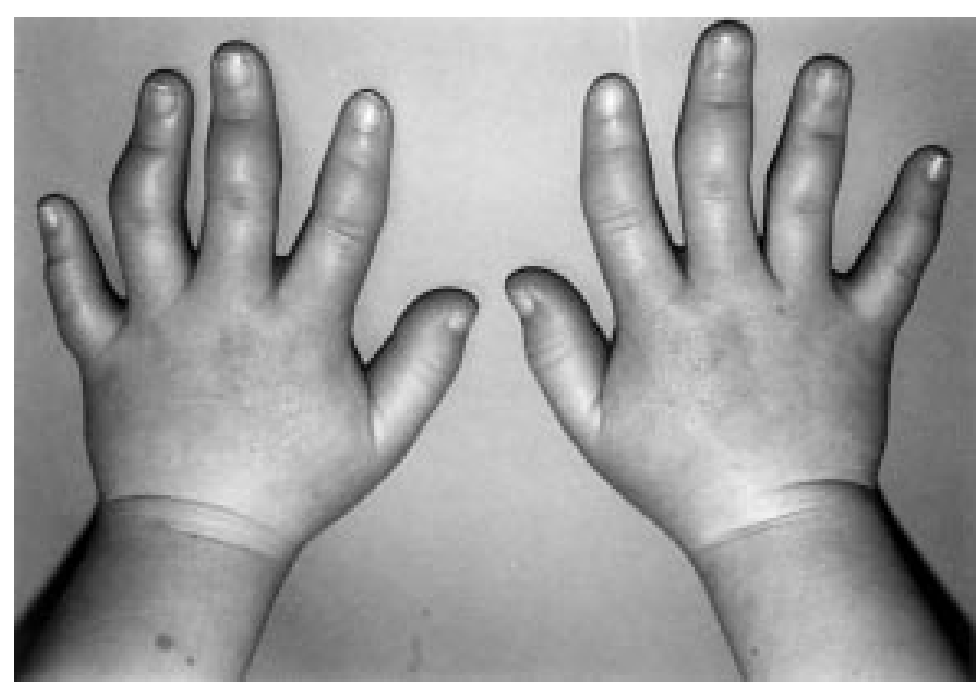

Figure 1 Dorsal view of hands of the proband (000) aged 10 years showing generally short digits, most apparent in the middle phalanges, and variable radial and ulnar clinodactyly.

Table 1 Selected measurements in centimetres and their centiles for patients identified by their pedigree number (fig 3)

\begin{tabular}{llllllllllll}
\hline Case & Sex & Age & Status & Height & Centile & Hand & \multicolumn{2}{c}{ Centile* } & Midfinger Centile & Foot & Centilet \\
\hline 002 & $\mathrm{~F}$ & 5 & Affected & 107.7 & 50 & 12 & 25 & 4.5 & -3 & 17 & 50 \\
000 & $\mathrm{~F}$ & 10 & Affected & 131.3 & 15 & 13.2 & -3 & 5.3 & -3 & 18.2 & -3 \\
008 & $\mathrm{~F}$ & 28 & Affected & 154.5 & 10 & 16.3 & -3 & 6.8 & -3 & 22.5 & 20 \\
010 & $\mathrm{~F}$ & 33 & Affected & 154 & 10 & 16.3 & -3 & 6.7 & -3 & 20.5 & -3 \\
105 & $\mathrm{~F}$ & 45 & Affected & 152.4 & 5 & 16 & -3 & 6.7 & -3 & 22.5 & 20 \\
111 & $\mathrm{~F}$ & 51 & Affected & 148.6 & -3 & 16.1 & -3 & 6.4 & -3 & 22 & 15 \\
202 & $\mathrm{~F}$ & 69 & Affected & 151.8 & -3 & 15.6 & -3 & 6.6 & -3 & 21.3 & 3 \\
007 & $\mathrm{M}$ & 25 & Affected & 174.5 & 50 & 18.5 & 50 & 7.3 & -3 & 25.2 & 25 \\
101 & $\mathrm{M}$ & 34 & Affected & 172.3 & 25 & 18.5 & 30 & 7.5 & 10 & 26 & 50 \\
011 & $\mathrm{~F}$ & 11.3 & Unaffected & 142 & 30 & 16.5 & 55 & 7 & 55 & $?$ & $?$ \\
003 & $\mathrm{~F}$ & 12.8 & Unaffected & 158.1 & 75 & 17.2 & 50 & 7.4 & 50 & 22.7 & 20 \\
005 & $\mathrm{~F}$ & 21 & Unaffected & 154.9 & 10 & 17.8 & 30 & 7.4 & 15 & 21.6 & 5 \\
009 & $\mathrm{~F}$ & 29 & Unaffected & 155.3 & 15 & 17.6 & 25 & 7.2 & 3 & 23.2 & 25 \\
001 & $\mathrm{M}$ & 6.3 & Unaffected & 117 & 50 & 13.5 & 60 & 5.4 & 50 & 17.5 & 50 \\
004 & $\mathrm{M}$ & 15.8 & Unaffected & 177.8 & 75 & 19.7 & 75 & 8.2 & 70 & 28.1 & 97 \\
103 & $\mathrm{~F}$ & 37 & Indeterminate & 158.8 & 30 & 17.1 & 15 & 7 & -3 & 23.1 & 25 \\
109 & $\mathrm{~F}$ & 50 & Indeterminate & 149.9 & -3 & 16.6 & 3 & 6.9 & -3 & 23.5 & -3 \\
006 & $\mathrm{M}$ & 26 & Indeterminate & 165.1 & 10 & 17.9 & 20 & 7.3 & 5 & 24.2 & 5 \\
107 & $\mathrm{M}$ & 46 & Indeterminate & 162.6 & 5 & 18.5 & 35 & 7.4 & 15 & 24 & 5 \\
\hline
\end{tabular}

${ }^{\star}$ Centiles are based upon combined male and female to age 16 years.

†Norms are limited to a maximum of 16 years. affected members were shortened middle and distal phalanges, proximal 1st phalanges, and 5th metacarpals. The feet were similarly involved and tended to have a broad, slightly adducted forefoot. The two affected children showed multiple coned epiphyses. This paper provides a detailed description of the family including the radiographic signs and metacarpophalangeal profiles, which proved to be useful in distinguishing the mildly affected persons.

(f Med Genet 2000;37:292-296)

Keywords: brachydactyly A1; metacarpophalangeal profile

Brachydactyly may occur as an isolated condition or as a part of a complex syndrome. In isolated brachydactyly the outstanding features are shortened or malformed digits that are thought to arise from abnormal growth of the phalanges or metacarpals or both. The recognition of characteristic patterns of bone involvement has permitted classification of the brachydactylies into specific types. ${ }^{1-3}$

Brachydactyly type A1 (BDA1), ${ }^{1}$ also referred to as Farrabee or Fitch type $9,{ }^{3}$ is characterised by shortness or absence of the middle phalanges of the hands and feet. While all the small tubular bones tend to be reduced in size, there is a disproportionate shortness of the middle phalanges and the proximal 1st phalanges. The 2 nd and 5 th middle phalanges tend to be the most severely affected, while the 4 th and 5th are the most likely of the metacarpals and metatarsals to be involved. Radial/ ulnar clinodactyly may also be seen, as well as malformed or absent epiphyses. ${ }^{2}{ }^{3}$ Patients are often short, thus supporting the view that this is a generalised dysplasia. Families with additional clinical signs have been documented, with scoliosis and abnormal menisci, ${ }^{4}$ and a more severe phenotype with generalised skeletal abnormalities and nystagmus. ${ }^{25}$ BDA1 is inherited in an autosomal dominant fashion and was the first recognised human Mendelian condition.

The phenotypes of the few published families with BDA 1 have been quite variable. In this paper we provide a description of members from an extended family with BDA1, nine affected, six unaffected, and four we have called "indeterminate" because initially we could not decide their status on clinical grounds. Following metacarpophalangeal profile analysis it was concluded that all four were affected. 


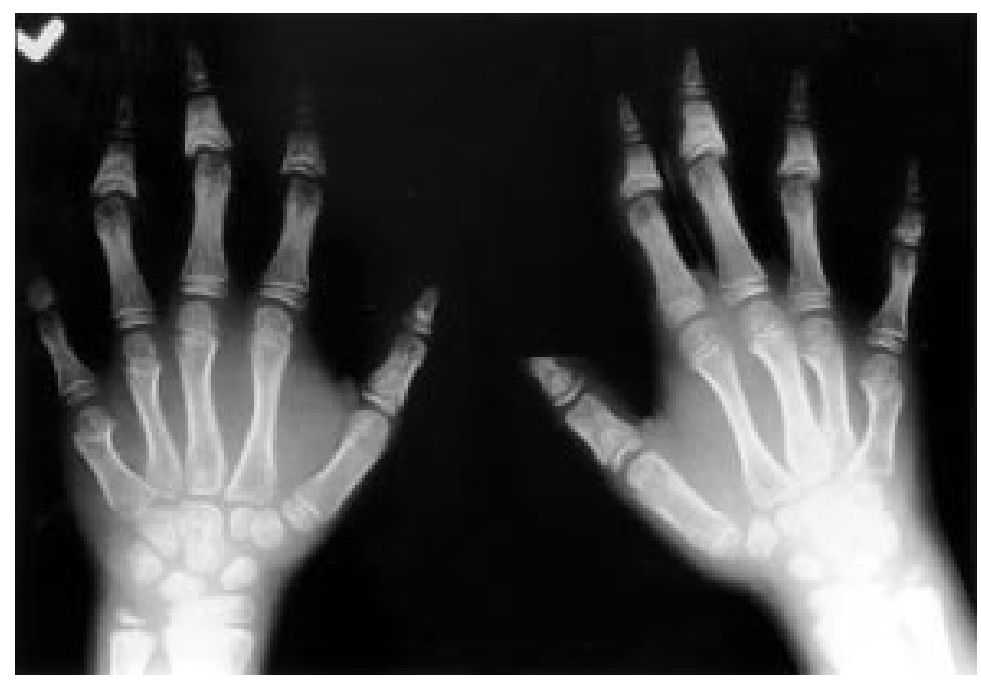

Figure 2 Radiographs of the proband aged 8 years. Shortness is most apparent in all middle, the proximal and distal 1st phalanges, and the 4th and 5th metacarpals. Premature fusion and cone shaped deformities of the affected epiphyses are seen.

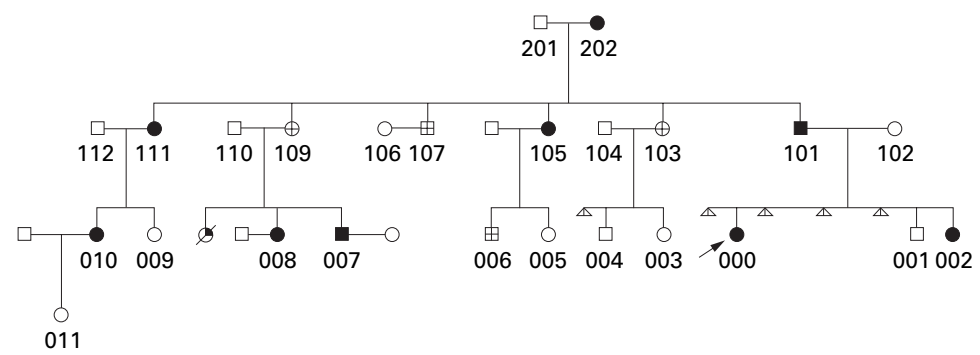

\begin{abstract}
- Brachydactyly type A1
- Reported as affected

$\boxplus \oplus$ Indeterminate

$\triangle$ Spontaneous abortion
\end{abstract}

Figure 3 Pedigree of the family members included in this paper.

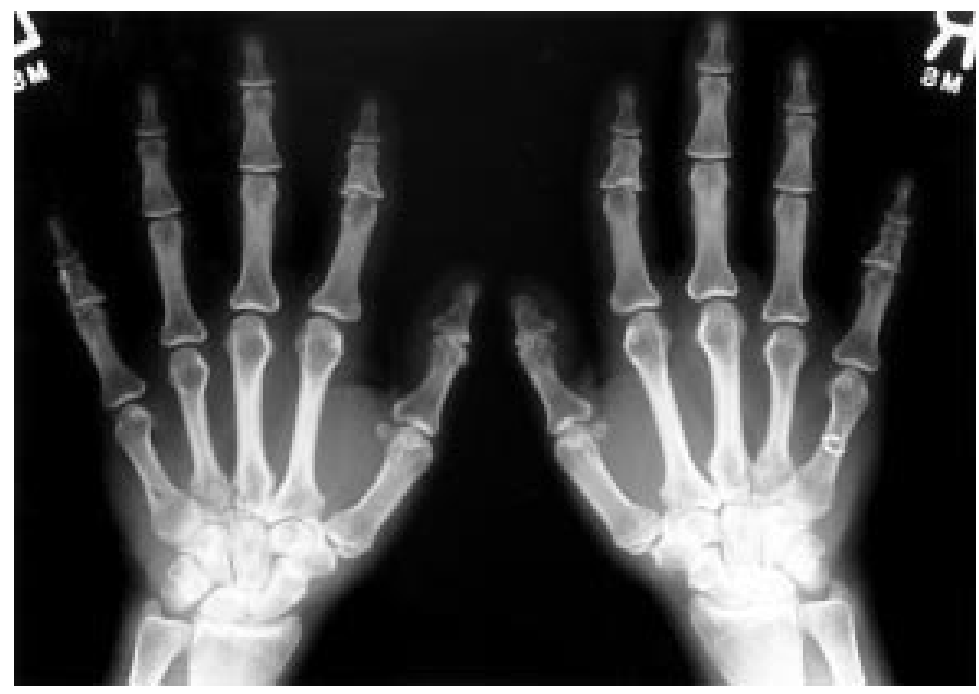

Figure 4 Adult female aged 45 years (fig 3, 105). PA radiograph of both hands. They are small overall with particular shortness of the 2nd and 5th middle phalanges, and to a lesser degree of the 1 st and 2 nd distal phalanges and of the 5th metacarpals.

\section{Case report}

The family was ascertained through an 8 year old girl who was referred to our genetics clinic for evaluation of her "abnormal hands". The prenatal history was unremarkable. At birth she was described as having excess mucus in her lungs and was noted to have a large, dark, hairy naevus on her upper right arm and an overfolded left upper helix. Subsequent growth and development were normal, with the exception of her short digits which displayed some ulnar and radial clinodactyly (fig 1). During childhood she had recurrent ear and bladder infections. The latter were attributed to a small bladder diverticulum. Her naevus was surgically removed. Measurements taken at the time of the study (aged 10 years) are summarised in table 1 , and confirmed relatively short stature with hands and feet below the 3 rd centile.

Radiographs of her hands showed them to be small with bilateral and disproportionate shortness of the 2 nd to 5 th middle phalanges, both proximal and distal 1st phalanges, and the 5th metacarpal (fig 2). There was premature fusion of the epiphyses of the $2 \mathrm{nd}$, $3 \mathrm{rd}$, and 4 th middle phalanges of the right hand and the 2nd to 5th of the left. The epiphyses of the 1st proximal and distal phalanges were coned. Ulnar deviation of the right 2 nd to 4 th proximal, and radial deviation of the left 4 th proximal interphalangeal joints were also apparent. Her feet showed changes similar to those of her hands, but without clinodactyly. The carpal and tarsal bones were normal. A skeletal survey showed no other abnormalities. Her clinical and radiological findings were considered diagnostic of BDA1.

The father of the proband was noted to be similarly affected and the parents reported that several family members had similar hands.

\section{FAMILY STUDY}

The study was conducted after approval by the Children's Hospital of Eastern Ontario Ethics Review Committee. After informed consent was obtained from each participating member, a personal medical history and physical examination was conducted. Hands, and sometimes feet, were photographed. Measurements included height, arm span, lower segment, hand length, middle finger length, and foot length. The hands of all participants were radiographed, as well as the feet, hips, and shoulders in a selected subset. An initial judgement, based upon clinical signs and the hand radiographs, as to whether or not the person was affected was then made by CMA and AGWH (fig 3). Complaints related to the hands or joints were limited to two members who reported "hand pains", although one 46 year old male (107) had radiographic evidence of arthritis of the hips. No-one had any of the findings associated with the more complex published cases of BDA1. There was no other significant medical history, other than asthma, reported by more than one person.

The height, foot, hand, and middle finger lengths and their centiles of the additional family members studied are summarised in table 1. Span minus height and upper/lower segment ratio varied randomly within the normal ranges (data not shown). The most consistent clinical sign among affected family members was short middle phalanges (fig 4). 


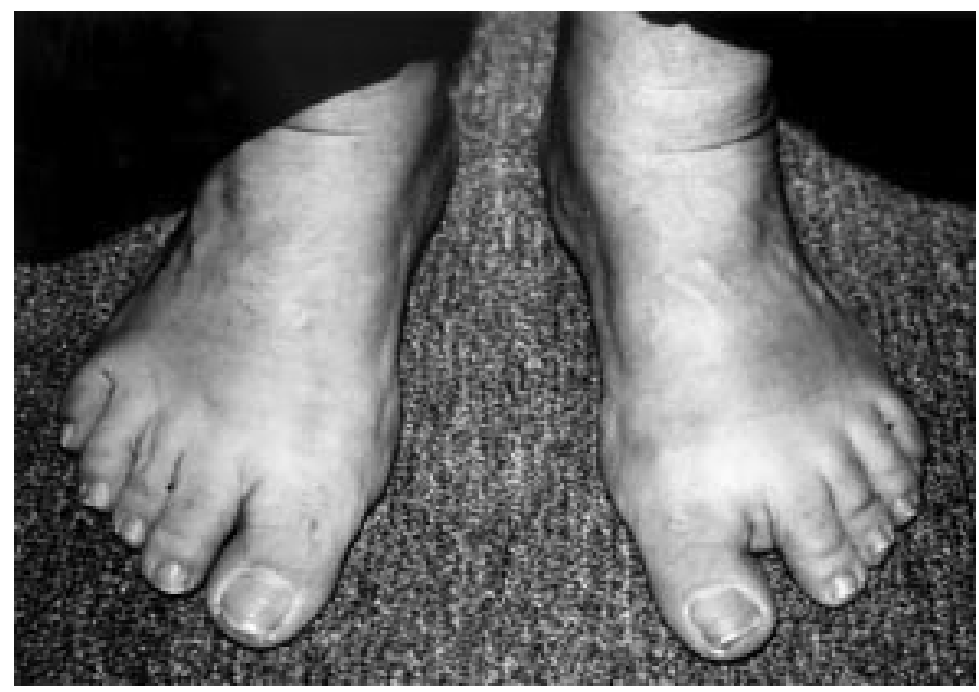

Figure 5 Typical foot from adult in the family showing short toes, increased 1st-2nd interdigital space, and relatively broad and slightly adducted forefoot.

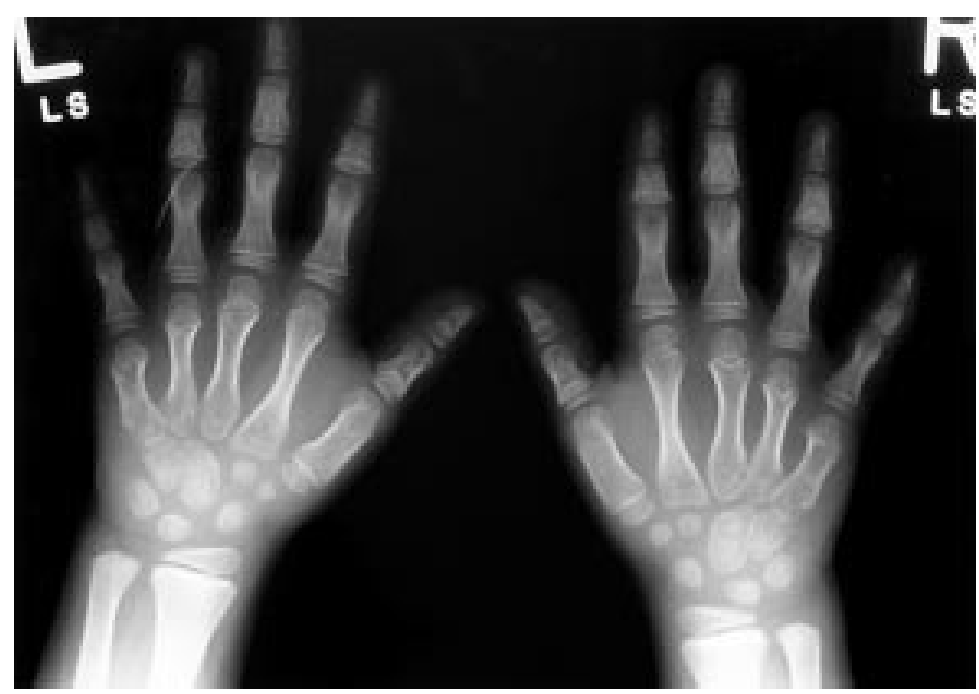

Figure 6 Girl (fig 3,002) aged 5 years. PA radiographs of both hands. They are small with variable shortness of the 2 nd-5th middle phalanges, of the 1 st proximal and distal phalanges, and of the 4th and 5th metacarpals, with early fusion and cone shaped deformities of the affected epiphyses. Her affected status was not recognised until the radiographs were examined.

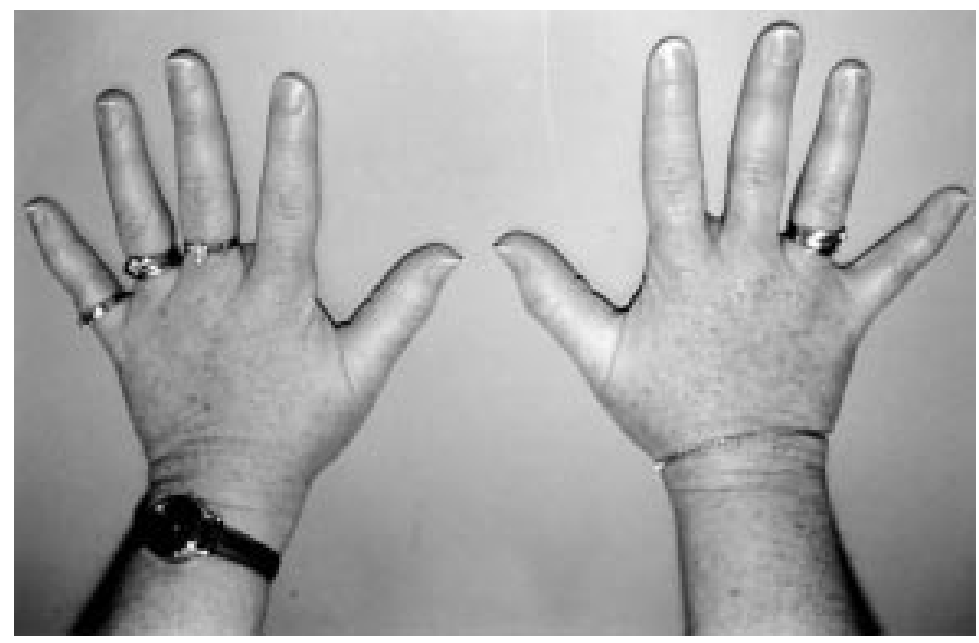

Figure 7 Hands of 103, one of the indeterminate group, showing small hands but no disproportion or clinodactyly.
Several also had clinodactyly of one or more digits, a very broad distal hallux, and a very broad, slightly adducted forefoot (fig 5). Coned epiphyses or evidence of premature fusion of the growth plates involving the middle phalanges was common in the children (figs 1 and 6). Although most members of the family could be clinically judged as affected or unaffected, a number were difficult to assign and were initially considered indeterminate. These persons were short with proportionally small hands but lacked significant clinodactyly or obviously greater involvement of the middle phalanges (fig 7).

A metacarpophalangeal pattern profile $(\mathrm{MCPP})^{78}$ was performed on each participant in order to provide a more objective assessment of the relative bone lengths. The MCPP is a plot of the age related standard deviations of the length of each hand bone. The phalanges and metacarpals from a right hand radiograph were measured to within $\pm 0.5 \mathrm{~mm}$ using a divider and steel $\mathrm{cm}$ scale and analysed using Antro $^{\mathrm{TM}}$. The metacarpophalangeal profile of each group is shown in fig $8 \mathrm{~A}, \mathrm{~B}$, and $\mathrm{C}$. Those who were considered clinically affected showed a characteristic pattern. Almost every measurement falls into the negative range of standard deviations (fig 8A). All middle and the 1 st distal phalanges are below $-2.0 \mathrm{SD}$, as are the majority of scores for the 1st proximal phalanges and 5th metacarpals. Unaffected subjects show the expected scatter around the mean with most measurements between +1.0 and $-1.0 \mathrm{SD}$ and no pattern (fig 8B). In contrast, the profiles of the four subjects who were classified clinically as "indeterminate" had all measurements below the mean, with a trend to greater involvement of the middle and distal 1st phalanges (fig 8C). Their mean pattern closely matched that of the affected subjects with the most notable difference being less involvement of the 2 nd middle phalanges (fig 9).

Independent of the clinical and MCPP analysis, the radiographs of six affected, two unaffected and the four indeterminate patients were evaluated by a paediatric radiologist for manifestations of BDA1. The findings are summarised in table 2 . In one person who we had considered indeterminate (fig 3, 103) comment was limited to the short 5 th middle phalanx, and in another (fig 3, 006) shortness of metacarpals 3-5 was noted but there was no comment made on any other phalanges.

\section{Discussion}

The family reported in this paper displays an autosomal dominantly inherited brachydactyly with the characteristics of type A1, namely principal involvement of the middle phalanges and frequent short proximal 1 st phalanges and 5 th metacarpals. Less typical was the constant shortness of the 1 st distal phalanges. Our family represents a mild phenotype. The middle phalanges are short, not absent, and, in even the most affected subjects, the clinical appearance seems less marked than that of many patients reported. Furthermore, there were four persons in whom we were initially unsure 

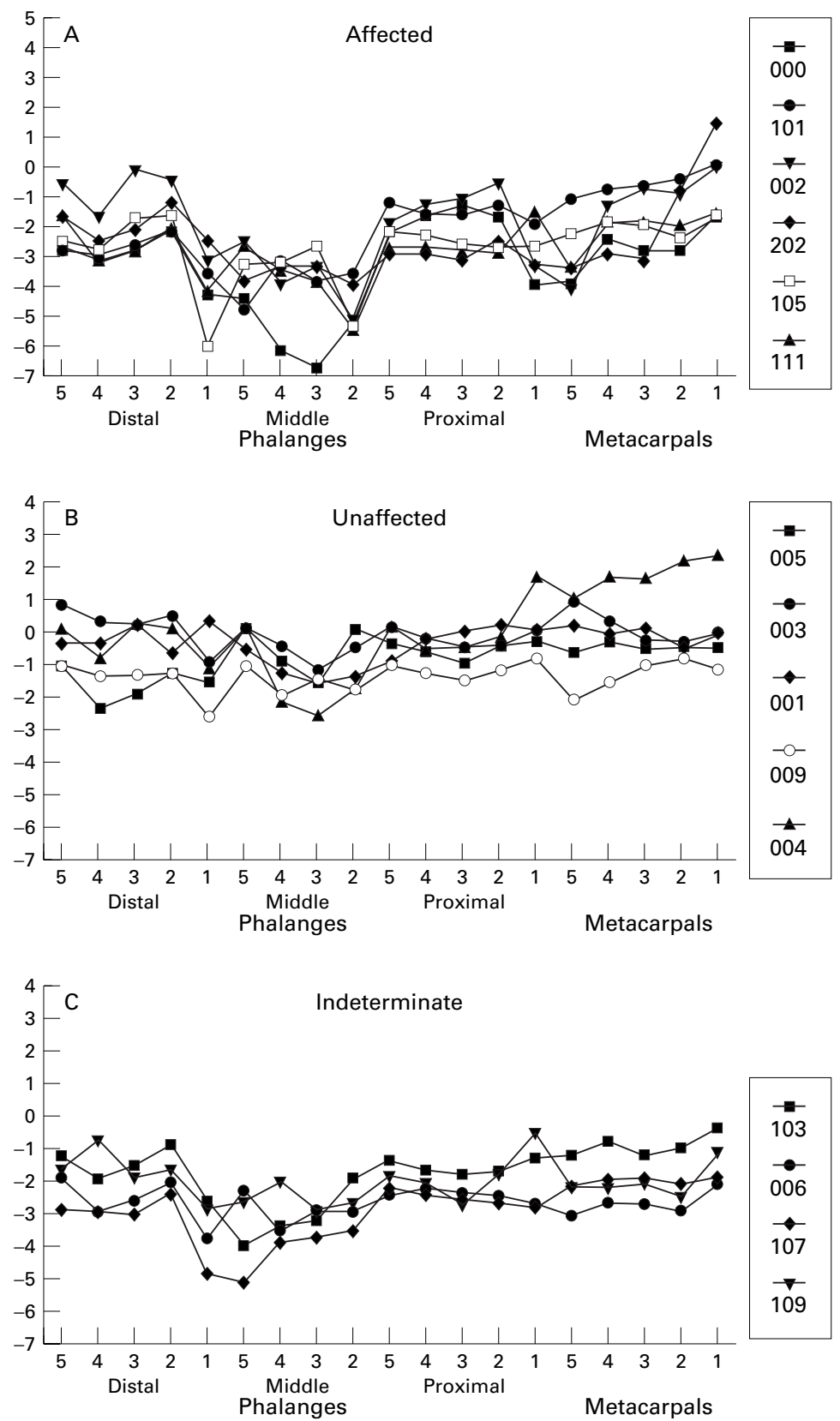

Figure 8 Individual metacarpophalangeal profiles (MCPP) (A) of the affected family members, (B) unaffected, and (C) the indeterminate group. Affected members 007, 008, 010, are not included but were typical.

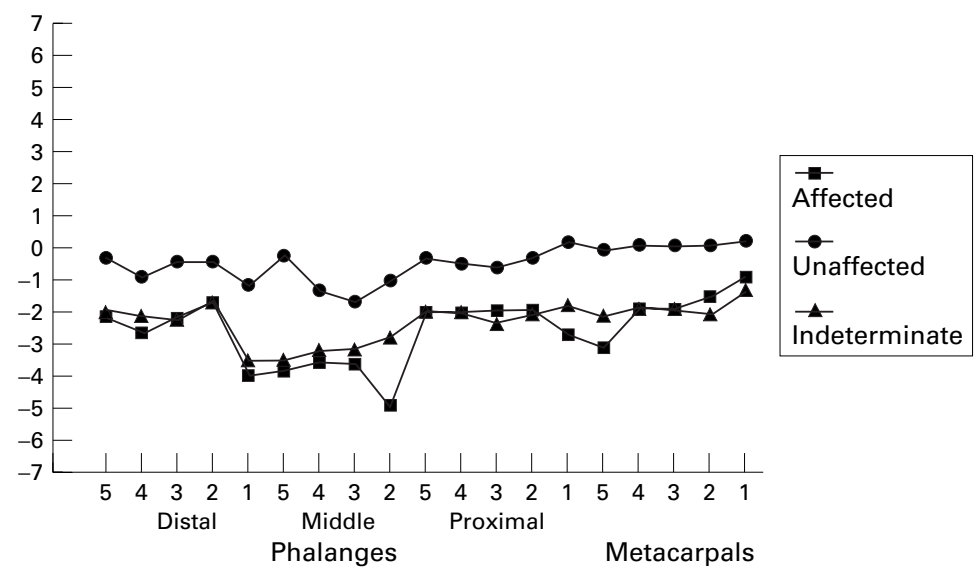

Figure 9 Mean MCPP for the three patient groups. of their clinical status. Short stature is common in BDA1 and appears to some extent in our family (table 1 ). Eight of the 13 affected are $<=10$ th centile and two are on, but none above, the 50th centile. Of the six unaffected, three are at or above the 50th centile and one is on, but none are below, the 10th centile. One of the affected who is on the 50th centile is a 5 year old girl and it will be of interest to see if she maintains her growth rate.

No-one in this family displayed any of the numerous anomalies seen in other families with BDA1. These have included abnormal menisci and scoliosis in three generations, ${ }^{4}$ bilateral 6th nerve palsy, nystagmus, scoliosis and club feet, ${ }^{2}$ more recently reported again in a member of a family thought to be descendants of the Drinkwater family. ${ }^{59}$ It has been suggested that the similarities seen in these two families represent a more extreme phenotype. Other complex phenotypes include that observed by Tsukahara $e t a l^{10}$ with dwarfism, ptosis, hearing loss, microcephaly, and mental retardation. Fukushima et $a l^{11}$ reported BDA1 in a patient with Klippel-Feil anomaly and a de novo apparently balanced 5;17 translocation. A sib of 007 and 008 (fig 3) was said to have died as a neonate of a chromosomal abnormality and to have had short fingers and multiple congenital anomalies including tetralogy of Fallot and a Klippel-Feil anomaly. The latter was confirmed from an original radiographic report, but we have been unable to obtain details or confirmation of the chromosome anomaly. In some cases these more complex phenotypes may represent contiguous gene syndromes.

We carried out a number of measurements in our family and the ratio of span to height and upper to lower segments did not suggest any overall body disproportion. While short stature was found in the family, there was some overlap with unaffected subjects. Similarly, while seven of the 13 affected persons had a total hand length $<=3$ rd centile and six of the total foot measurements were $<=5$ th centile, both these measurements also overlapped with the unaffected group for some subjects. Middle finger length, where 10 of the measurements were $<3$ rd centile, was perhaps the most reliable single measure and, combined with clinodactyly of other than the commonly involved 5 th digit, would allow most cases to be ascertained. However, it should be noted that one unaffected person also had a middle finger length at the 3 rd centile.

We believe that radiological evaluation remains crucial to accurate diagnosis within an affected family. An experienced radiologist will make the diagnosis from careful review of hand films in most cases, even those that are relatively mild. However, the metacarpophalangeal profile allows a more quantitative and objective means of diagnosis and has been used in the diagnosis of several syndromes which display characteristic patterns, such as Holt-Oram and Turner syndromes. ${ }^{7}$ In our family all subjects classified clinically as affected showed a typical MCCP profile, and this profile was used to show that all four cases 
Table 2 A summary of the interpretation of the radiological findings in the 12 family members examined by the radiologist

\begin{tabular}{|c|c|c|c|c|c|c|c|}
\hline $\begin{array}{l}\text { Patient, } \\
\text { pedigree, } \\
\text { E'status }\end{array}$ & $\begin{array}{l}\text { Short } \\
\text { metacarpals }\end{array}$ & $\begin{array}{l}\text { Short } \\
\text { proximal } \\
\text { phalanges }\end{array}$ & $\begin{array}{l}\text { Short } \\
\text { middle } \\
\text { phalanges }\end{array}$ & $\begin{array}{l}\text { Short } \\
\text { distal } \\
\text { phalanges }\end{array}$ & Cone shaped epiphyses & $\begin{array}{l}\text { Radial/ulnar } \\
\text { deviation of } \\
\text { phalanges }\end{array}$ & Other \\
\hline $101(\mathrm{~A})$ & & & $2 \& 5$ & & & dp 3 & MT-1 varus, hallux valgus, short prox phal toes \\
\hline 111 (A) & & & $2 \& 5$ & & & & MT-1 varus, hallus valgus, short prox phal toes $3-5$ \\
\hline $000(\mathrm{~A})$ & $5>4$ & 1 & $2-5$ & 1 & $\mathrm{mc} 5, \mathrm{pp} 1, \mathrm{dp} 1, \mathrm{mp} 2-5$ & $\mathrm{mp} 2-4$ & \\
\hline $002(\mathrm{~A})$ & 4,5 & 1,5 & $2-5$ & 1 & $\mathrm{mc} 3 \& 4, \mathrm{dp} 1, \mathrm{pp} 1 \& 5, \mathrm{mp} 3 \& 4$ & & \\
\hline 105 (A) & 5 & & 2,5 & $1>2$ & & $\operatorname{mp} 2$ & Generally short fingers \\
\hline $202(\mathrm{~A})$ & $3-5$ & & 2,5 & & & & Generally short fingers \\
\hline 103 (In) & & & 5 & & & & \\
\hline 109 (In) & $2-5$ & $2-5$ & $2-5$ & & & dp 3 & Generally rather short fingers \\
\hline 107 (In) & $3,4, \& 5$ & & $2 \& 5$ & 2 & & & Degenerative hip arthritis \\
\hline 006 (In) & $3,4, \& 5$ & & & & & & \\
\hline 004 (Ua) & & & & & & dp 3 & Under tubulation mc 2 , small tuft dp 5 \\
\hline $001(\mathrm{Ua})$ & & & & & & & \\
\hline
\end{tabular}

$\mathrm{A}=$ affected clinically and by MCPP, In = indeterminate clinically but affected by MCPP, Ua = unaffected clinically and by MCPP.

$\mathrm{pp}=$ proximal, $\mathrm{mp}=$ middle, $\mathrm{dp}=$ distal phalanx, $\mathrm{MT}=$ metatarsus adductus.

considered indeterminate were actually affected. Attempts to develop a diagnostic ratio of specific affected phalanges/metacarpals to those bones generally unaffected was not successful and we believe the MCPP itself is the most useful approach.

Temtamy and McKusick ${ }^{2}$ argued that shortness limited to the middle phalanges of the 2nd and 5 th digits was a separate entity that they called brachydactyly A4 (BDA4). Fitch ${ }^{3}$ considered that BDA4 was actually a mild expression of BDA1. Our family does not provide evidence to support the latter argument. Despite significant interpersonal variability, there was no trend for the milder affected subjects to show the pattern of BDA4 (fig 8A, C). Isolation of the gene(s) responsible should allow this question to be addressed definitively.

No gene or locus has yet been cloned or mapped for BDA1. Several candidate genes, $M S X 1, M S X 2, H O X D, F G F-1$, and $F G F-2$, have been ruled out in at least one family. ${ }^{12} \mathrm{We}$ are at present obtaining blood from additional members of this family and have begun linkage studies.

We would like to thank the many members of this family who took time to meet us, especially $\mathrm{Mrs} \mathrm{C}$ who helped to encourage involvement of the family and obtained working space for us at a local hospital. We are indebted to Dr Pater McDonald, paediatric radiologist, for his careful and detailed review of the radiographs and for his helpful suggestions for the manuscript. We would also like to thank Dr Mohamed Khalifa and Ms Susan Cappon who examined member 010 and arranged for her photographs and radiographs.

1 Bell J. On brachydactyly and symphalangism. Treasury of Human Inheritance 1951;5:1-30.

2 Temtamy SA, McKusick VA. Brachydactyly as an isolated malformation. In: Bergsma D, Mudge JR, Paul NW, malformation. In: Bergsma D, Mudge JR, Paul NW, Greene SC, eds. The genetics of hand malformations. New 1978; XIV:187-97.

3 Fitch N. Classification and identification of inherited brachydactylies. F Med Genet 1979;16:36- 44

4 Raff ML, Leppig KA, Rutledge JC, Weinberger E, Pagon RA. Brachydactyly type A1 with abnormal menisci and scoliosis in three generations. Clin Dysmorphol 1998;7:2934

5 Slavotinek A, Donnai D. A boy with severe manifestations of type A1 brachydactyly. Clin Dysmorphol 1998;7:21-7.

6 Bateson W. Mendel's principles of heredity. Cambridge: Cambridge University Press, 1913:210-15.

7 Poznanski AK, Garn SM, Nagy JM, Gall JC. Metacarpophalangeal pattern profiles in the evaluation of skeletal malformations. Radiology 1972;104:1-11

8 Garn SM, Hertzog KP, Poznanski AK, Nagy JM. Metacarpophalangeal length in the evaluation of skeletal malformation. Radiology 1972;105:375-81.

9 Drinkwater H. A second brachydactylous family. 7 Genet 1915;4:323-48.

10 Tsukahara M, Azuno Y, Kajii T. Type A1 brachydactyly, dwarfism, ptosis, mixed partial hearing loss, microcephaly, and mental retardation. Am f Med Genet 1989;33:7-9.

11 Fukushima Y, Ohashi H, Wakui K, Nishimoto H, Sato M, Aihara T. De novo apparently balanced reciprocal translocation between $5 \mathrm{q} 11.2$ and $17 \mathrm{q} 23$ associated with KlippelFeil anomaly and type A1 brachydactyly. Am $\mathcal{F}$ Med Genet 1995;57:447-9.

12 Mastrobattista JM, Dolle P, Blanton SH, Northrup H. Evaluation of candidate genes for familial brachydactyly. $\mathcal{F}$ Med Genet 1995;32:851-4. 